\title{
Study on the Electrochemical Corrosion Behavior of 304 Stainless Steel in Chloride Ion Solutions
}

\author{
Yu Zhang ${ }^{1}$, Changdi Yang ${ }^{1}$, Lin Zhao ${ }^{2, *}$, Jiwen Zhang ${ }^{1}$ \\ ${ }^{1}$ School of Mechanical Engineering, Shenyang University, Shenyang 110044, China \\ ${ }^{2}$ Institute of Metal Research, Chinese Academy of Sciences, Shenyang, 110016, China \\ *E-mail: zhaolin@imr.ac.cn
}

doi: $10.20964 / 2021.02 .01$

Received: 25 July 2020 / Accepted: 24 November 2020 / Published: 31 December 2020

The corrosion behavior of 304 stainless steel under different concentrations of $\mathrm{Cl}^{-}$and specific $\mathrm{Fe}^{3+}$ was studied with different immersion times by open-circuit potential, AC impedance, and cyclic voltammetry curves. The results show that with an increase in the concentration of $\mathrm{Cl}^{-}$in the solution, the stability of 304 stainless steel with the passive film decreased. The potential time curve shows that in the initial stage, the incubation process of pitting can be described by exponential relationship. At the initial stage of immersion, the passive film of austenitic stainless steel hindered the corrosion of $\mathrm{Cl}^{-}$to some extent, but by prolonging the immersion time, $\mathrm{Cl}^{-}$destroyed the integrity of the passive film on the surface of austenitic stainless steel, and eventually led to apparent pitting corrosion.

Keywords: 304 stainless steel; passive film; concentration of $\mathrm{Cl}^{-}$; pitting corrosion

\section{FULL TEXT}

(C) 2021 The Authors. Published by ESG (www.electrochemsci.org). This article is an open access article distributed under the terms and conditions of the Creative Commons Attribution license (http://creativecommons.org/licenses/by/4.0/). 